\title{
Simulation of high-resolution WRF model for an extreme rainfall event over the southern part of Thailand
}

\author{
Pramet Kaewmesri ${ }^{1}$, Usa Humphries ${ }^{1,}{ }^{*}$, Sirapong Sooktawee ${ }^{2}$
}

${ }^{1}$ Department of Mathematics, Faculty of Science, King Mongkut's University of Technology Thonburi (KMUTT), 126 Pracha-Uthit Road, Bang mod, Thung khru, Bangkok 10140, Thailand

${ }^{2}$ Environmental Research and Training Center, Department of Environmental Quality Promotion, Ministry of Natural Resources and Environment, Bangkok 10400, Thailand

\section{A R T I C LE IN F O}

\section{Article history:}

Received 26 April 2017

Received in revised form

21 July 2017

Accepted 25 July 2017

\section{Keywords:}

Microphysics parameterization schemes

Thai meteorological department Tropical rainfall measure mission Weather research and forecasting

\begin{abstract}
A B S T R A C T
The aim of research was to examine sensitivity to different microphysics parameterization schemes (Kessler, Lin, WSM3, WSM5 and WSM6) available in the Weather Research and Forecasting (WRF) model in the high-resolution heavy rainfall prediction. The Ensemble means technique was used to improve the results from the model in this case. The period was focused in November 2011. The different microphysics showed good agreements with observation from Tropical Rainfall Measure Mission (TRMM) and Thai Meteorological Department (TMD) station data. However, the Lin scheme performed that the good values of the Mean Absolute Error (MAE) and the Correlation Coefficient (CORR) were 1.16(0.39) and 0.88(0.61) to compare with TMD(TRMM) data. The Ensemble mean was an improved performance of heavy rainfall results that the good values of the (MAE) and the (CORR) were 1.03(0.16) and 0.92(0.67) to compare with TMD (TRMM) data. In summary, the WRF model demonstrated a good and reasonable rainfall simulation capability when to simulate were compared with the observations data over study areas. Detailed comparison indicates that Lin scheme and the Ensemble mean are highly recommended to simulate heavy rainfall.
\end{abstract}

(C) 2017 The Authors. Published by IASE. This is an open access article under the CC BY-NC-ND license (http://creativecommons.org/licenses/by-nc-nd/4.0/).

\section{Introduction}

The Northeast Monsoon occurs between midOctober and mid-February annually. This period of the year is quite cold in upper Thailand (particularly in December and January), but this coincides with heavy rainfall in the eastern and southern area of Thailand. So that, the southern part of Thailand has several unique characteristics of weather and climate. Because, the rainfall in the southern part of Thailand is influenced by the Northeast Monsoon (Wangwongchai et al., 2005; Kirtsaeng et al., 2012). Since, rainfall is the main source of fresh water for the agricultural water supply in the southern part of Thailand. However, sometime the rainfall is a component of severe weather, and natural disasters may be caused by heavy rainfall. For example two flash floods events were influenced by heavy rainfall. In 2005, Wangwongchai et al. (2005) investigated very heavy rainfall event over the southern part of

\footnotetext{
* Corresponding Author.

Email Address: usa.wan@kmutt.ac.th (U. Humphries) https://doi.org/10.21833/ijaas.2017.09.004

2313-626X/C 2017 The Authors. Published by IASE.

This is an open access article under the CC BY-NC-ND license

(http://creativecommons.org/licenses/by-nc-nd/4.0/)
}

Thailand. During the last ten days of November 2000, a strong heavy rainfall occurred in Hat Yai (A precipitation amount in November). There were $81.5,219.4,146.3$ and $102.2 \mathrm{~mm}$ per day on 20,21 , 22, and 23 November, respectively. In 2012, Kirtsaeng et al. (2012) simulated the heavy rainfalls over the southern part of Thailand on 5 November 2009.

In normally, Northeast monsoon, a cold surge crosses the South China Sea and flows to the cyclonic circulation over the southern part of Thailand and Malaysia Peninsula, which might be the main factor causing rainfall over this area (Kirtsaeng et al., 2012). Fig. 1 shows the wind direction and relative humidity from the National Centre for Environmental Prediction's (NCEP) observation data set. It shows streamlines and shaded areas of relative humidity in November 2011. The wind blew a cold surge from the South China Sea which flowed over the southern part of Thailand to the center of cyclonic circulation in the island of Borneo. This became the basis of the study on the heavy rainfall event in November 2011.

Fig. 2 shows the 25 TMD rainfall gauge stations over the southern part of Thailand and Table 1 describes their locations. The heavy rainfall event 
which occurred on November 2011 was considered significant meteorologically by the Thai Meteorological Department (TMD).

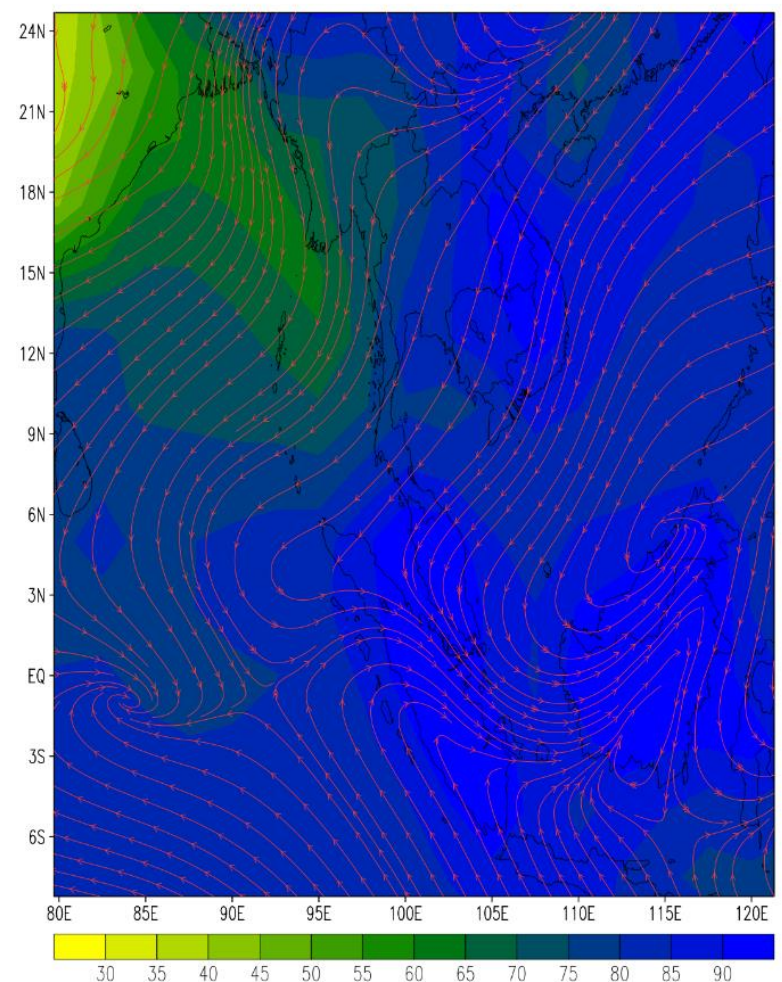

Fig. 1: Streamline and relative humidity (\%) in November 2011

The event was well measured with the conventional rainfall gauges of the TMD. The accumulated rainfall recorded by the 25 TMD stations between 1 and 30 November 2011 is shown in Fig. 3. Many areas recorded $300-600 \mathrm{~mm}$ of accumulated rainfall, such as Sawi Meteorological Station $(313 \mathrm{~mm})$, Nakhon Si Thammarat (491.7 $\mathrm{mm}$ ), Nakhon Si Thammarat Meteorological Station (560.4 mm), Phatthalung Meteorological station (583 mm), Khor Hong Ago Meteorological Station (562.2 mm), Songkhla (476.8 mm), Hat Yai Airport (399.2 mm), Pattani Airport (517.5 mm) and Yala Meteorological station $(608.1 \mathrm{~mm})$. The circumstances causing the unique weather over the southern part of Thailand create difficulties for the numerical weather prediction (NWP) model and the synoptic scale features along with a variety of physics parameterization schemes. It is due to these complexities that the use of a NWP model in a nested configuration is a major requirement for simulating and forecasting the rainfall occurrence over this region.

Therefore, improved rainfall prediction will be the main factor in helping to manage water. It will help people to minimize damage by warning in advance of heavy rainfall events. Good estimations of heavy rainfall are crucial to helping the risk management of natural disasters, in addition to improving water management. It is well recognized that one of the best options to improve the accuracy of rainfall simulation is to enhance and improve
NWP models. High-resolution numerical modelling techniques are needed to better predict heavy rainfall events and understand the mechanisms responsible for heavy rainfall. Therefore this study used physics parameterization to help improve the simulation of a heavy rainfall event. One of the necessary physics parameterizations was impact simulation heavy rainfall over high resolution that is microphysics parameterization scheme. Since microphysics parameterization showing processes in clouds (including water vapor, cloud water, cloud ice, snow, hail and rain).

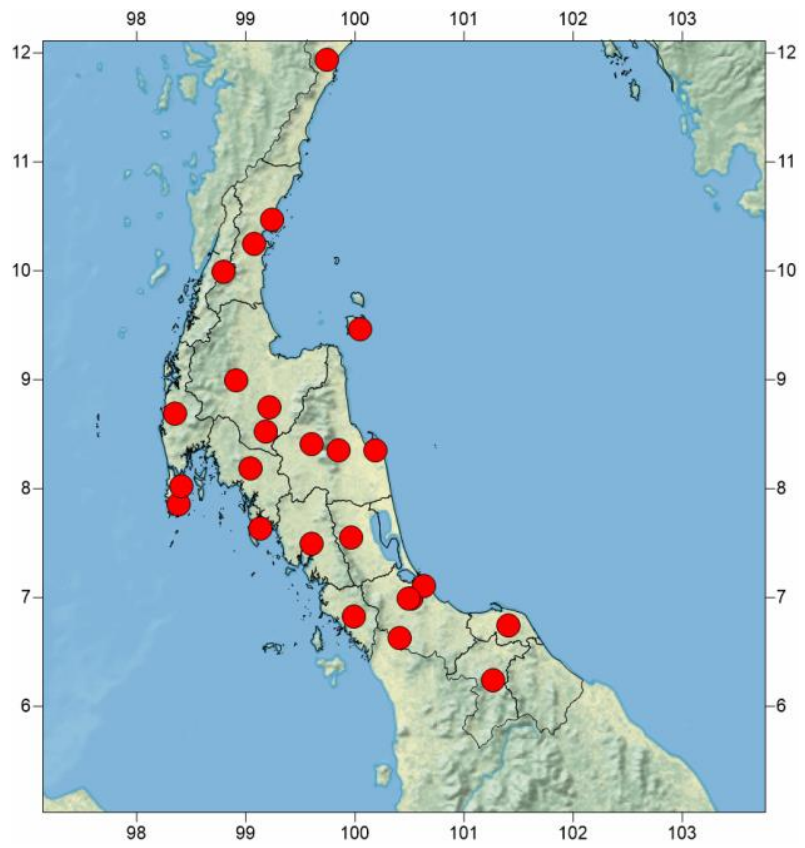

Fig. 2: The 25 TMD rainfall gauge stations over the southern part of Thailand

The main objectives of this study can be summarized as follows:

a) To simulate the heavy rainfall event which occurred over southern Thailand in November 2011 using different microphysics parameterizations schemes available in the WRF model. Therefore, this work investigates the influence of the Kessler scheme, Lin scheme, WSM3 scheme, WSM5 scheme WSM6 scheme and Ensemble mean.

b) The results of the simulations are compared with the rainfall amount from the TMD rainfall station data set and the TRMM data set, providing information for the improvement of rainfall simulations.

\section{Methodology}

The model used in this study is the Weather Research and Forecasting (WRF) model (Skamarock et al., 2008). This model is a famous dynamic atmospheric model. WRF is developed mainly by the US National Centre for Atmospheric Research (NCAR) with many other research and universities. 
WRF is depend on the Numerical Weather Prediction (NWP) and can be applied high resolution from meters to thousands of kilometers. The model configuration in this study was follows that of the
WRF regional climate model used in previous studies (Kirtsaeng et al., 2010; Efstathiou et al., 2012; El Afandi et al., 2013; Pennelly et al., 2014; Kaewmesri et al., 2017).

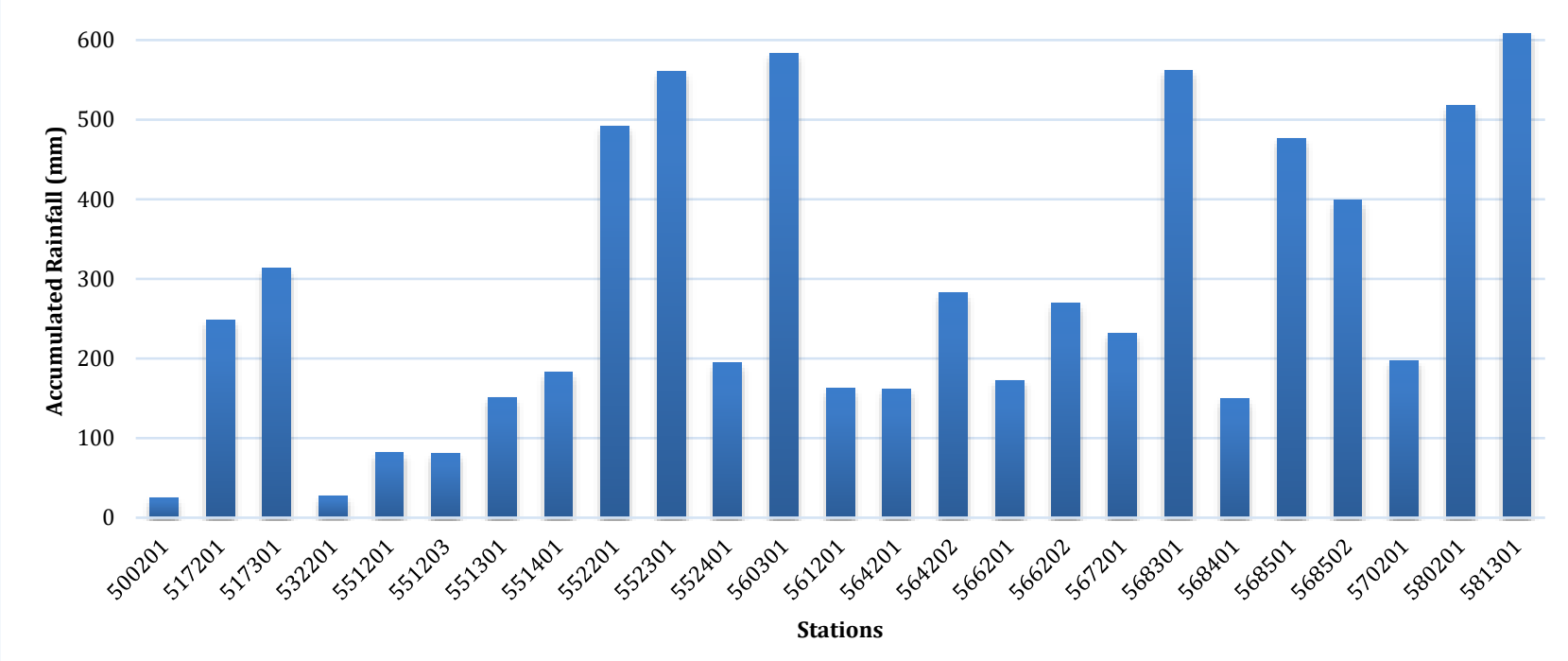

Fig. 3: The accumulated rainfall recorded by the 25 TMD stations, from 1 to 30 November 2011

The multi-nested domain experiments included three domains, as shown in Fig. 4. The horizontal resolution of the outer domain covered the southern part of Thailand, and the resolution was $36 \mathrm{~km}$ (128×104 grid points), which is reasonable in capturing the microphysics schemes. The domains were located between longitudes 79.710 degree east and 121.299 degree east and latitudes -8.218 degree north and 24.682 degree north. The sub-domain resolution was $12 \mathrm{~km}(114 \times 90$ grid points $)$ and covered the Indian Ocean and Gulf of Thailand. This domain was located between longitudes 94.338 degree east and 106.673 degree east and latitudes 3.758 degree north and 13.353 degree north. The innermost domain covered the southern part of Thailand, and the resolution was $4 \mathrm{~km}(183 \times 198$ grid points). This domain was located between longitudes 97.139 degree east and 103.761 degree east and latitudes 5.028 degree north to 12.111 degree north, with 27 layers in the vertical direction with a maximum of $50 \mathrm{hPa}$.

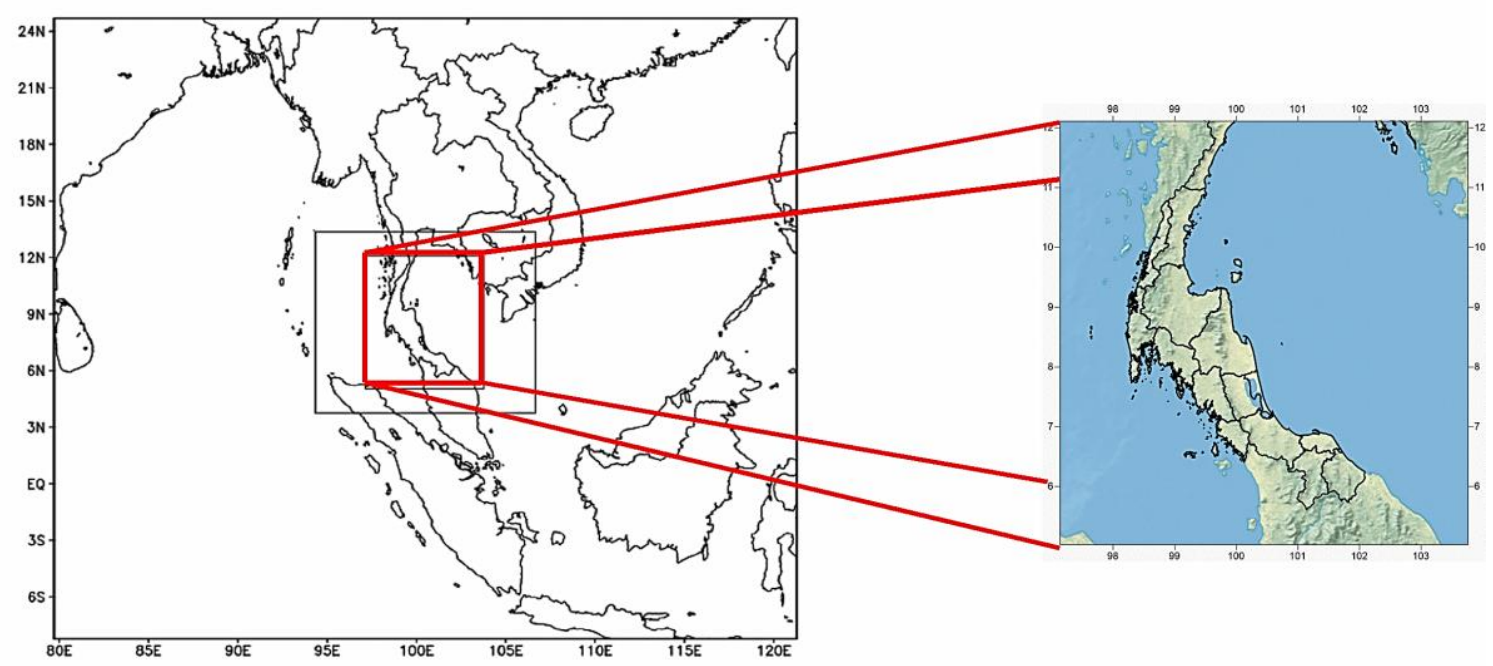

Fig. 4: The three nested modelling domains 1, 2 and 3, which have horizontal resolutions of 36, 12 and 4 km, respectively

The two-way nested domain was used to simulate the synoptic situation over the southern part of Thailand in November 2011. The physics parameterization used in this study were the Rapid Radiative Transfer Model (RRTM) scheme (Mlawer et al., 1997) for the long wave radiation scheme, the Dudhia scheme (Dudhia, 1989) for the short wave radiation scheme, the Noah Land-Surface Model for the land surface scheme (Tewari et al., 2004), the Yonsei University planetary boundary layer (YSU) scheme (Hong et al., 2005) for the Planetary Boundary Layer (PBL) scheme and the Kain-Fritsch scheme (Janjic, 1994) for cumulus parameter. This research was fixed cumulus scheme only on domain 1 and domain 2, while domain 3 was without a cumulus scheme (Lim and Hong, 2005). A different 
formulation of microphysics parameterization schemes used in this study is available in WRF-ARW: Kessler scheme (Kessler, 1995), Lin scheme (Lin et al., 1983), WSM3-class scheme (Hong et al., 2004), WSM5-class scheme (Hong et al., 2004), and WSM6class scheme (Hong and Lim, 2006). Table 2 summarizes the selected all of physics parameterization schemes and experimental design.

Table 1: The description of 25 TMD rainfall gauge station over southern Thailand

\begin{tabular}{|c|c|c|c|c|}
\hline No & Station & Station Name & Lat & Lon \\
\hline 1 & 500201 & Prachuap Khiri Khan & 11.9408 & 99.7399 \\
\hline 2 & 517201 & Chumpon & 10.4675 & 99.2403 \\
\hline 3 & 517301 & $\begin{array}{l}\text { Sawi Meterological } \\
\text { Station }\end{array}$ & 10.2451 & 99.0738 \\
\hline 4 & 532201 & Ranong & 9.9950 & 98.7962 \\
\hline 5 & 551201 & Surat Thani & 8.9943 & 98.9073 \\
\hline 6 & 551203 & Samui Island & 9.4668 & 100.0452 \\
\hline 7 & 551301 & $\begin{array}{l}\text { Surat Thani } \\
\text { Meterological Station }\end{array}$ & 8.7441 & 99.2126 \\
\hline 8 & 551401 & Phrasaeng & 8.5217 & 99.1848 \\
\hline 9 & 552201 & Nakhon Si Thammarat & 8.3549 & 99.8510 \\
\hline 10 & 552301 & $\begin{array}{l}\text { Nakhon Si Thammarat } \\
\text { Meterological Station }\end{array}$ & 8.3549 & 100.1840 \\
\hline 11 & 552401 & Chawang & 8.4105 & 99.6012 \\
\hline 12 & 560301 & $\begin{array}{l}\text { Phatthalung } \\
\text { Meterological station }\end{array}$ & 7.5488 & 99.9620 \\
\hline 13 & 561201 & Takuapa & 8.6885 & 98.3522 \\
\hline 14 & 564201 & Phuket & 7.8546 & 98.3799 \\
\hline 15 & 564202 & Phuket Airport & 8.0214 & 98.4077 \\
\hline 16 & 566201 & Lanta Island & 7.6322 & 99.1293 \\
\hline 17 & 566202 & Krabi & 8.1881 & 99.0460 \\
\hline 18 & 567201 & Trang Airport & 7.4932 & 99.6012 \\
\hline 19 & 568301 & $\begin{array}{c}\text { Khor Hong Ago } \\
\text { Meteorological Station }\end{array}$ & 6.9929 & 100.5171 \\
\hline 20 & 568401 & Sadao & 6.6315 & 100.4061 \\
\hline 21 & 568501 & Songkhla & 7.1040 & 100.6281 \\
\hline 22 & 568502 & Hat Yai Airport & 6.9929 & 100.4893 \\
\hline 23 & 570201 & Satun & 6.8261 & 99.9897 \\
\hline 24 & 580201 & Pattani Airport & 6.7427 & 101.4053 \\
\hline 25 & 581301 & $\begin{array}{l}\text { Yala Meterological } \\
\text { Station }\end{array}$ & 6.2423 & 101.2665 \\
\hline
\end{tabular}

Table 2: summarizes the selected all of physics parameterization schemes and experimental design

\begin{tabular}{|c|c|}
\hline Physic Parameterization & Selected \\
\hline Microphysics schemes & $\begin{array}{c}\text { Kessler, Lin, WSM3, WSM5, and } \\
\text { WSM6 }\end{array}$ \\
\hline Cumulus scheme & Kain-Fritsch \\
\hline $\begin{array}{l}\text { Long Wave Radiation } \\
\text { scheme }\end{array}$ & Rapid Radiative Transfer Model \\
\hline $\begin{array}{c}\text { Short Wave Radiation } \\
\text { scheme }\end{array}$ & Dudhia \\
\hline $\begin{array}{l}\text { Planetary Boundary Layer } \\
\text { scheme }\end{array}$ & $\begin{array}{c}\text { Yonsei University planetary } \\
\text { boundary layer }\end{array}$ \\
\hline Land Surface scheme & Noah Land-Surface Model \\
\hline Run period & November 2011 (1 month) \\
\hline
\end{tabular}

Statistical methods were used to compare simulation accuracy. The accuracy of each simulation was calculated using the Correlation Coefficient $(C O R R)$ and Mean Absolute Error (MAE). The techniques can be done for any scalar quantity. The $C O R R$ is defined by the following equation:

$\operatorname{CORR}=\frac{n \sum_{i=1}^{n} x_{i} y_{i}-\left(\sum_{i=1}^{n} x_{i}\right)\left(\sum_{i=1}^{n} y_{i}\right)}{\sqrt{n \sum_{i=1}^{n}\left(x_{i}^{2}\right)-\left(\sum_{i=1}^{n} x_{i}\right)^{2}} \sqrt{n \sum_{i=1}^{n}\left(y_{i=1}^{n}\right)-\left(\sum_{i=1}^{n} y_{i}\right)^{2}}}$,

where CORR is the correlation coefficient, $x$ is defined as the simulation value, $y$ is defined as the observation value and $n$ is defined as the number of $i$ pairs of observations and simulation values. The value of $r$ is such that $-1 \leq r \leq+1$. The + and signs are used for positive linear correlations and negative linear correlations, respectively. Positive correlation: if $x$ and $y$ have a strong positive linear correlation, $r$ is close to +1 . A $r$ value of exactly +1 indicates a perfect positive fit. Positive values indicate a relationship between $x$ and $y$ variables such that as values for $x$ increase, values for $y$ also increase, in the same direction. Negative correlation: $x$ and $y$ have a strong negative linear correlation, $r$ is close to-1. A $r$ value of exactly-1 indicates a perfect negative fit. Negative values indicate a relationship between $x$ and $y$ variables such that as values for $x$ increase (decrease), values for $y$ decrease (increase), in the opposite direction (Wilkins, 1995). The $M A E$ is defined by the following equation:

$M A E=\frac{1}{n} \sum_{i=1}^{n}\left|x_{i}-y_{i}\right|$,

where $M A E$ is mean absolute error, $x$ is defined as the simulation value, $y$ is defined as the observation value and $n$ is defined as the number of $i$ pairs of observations and simulation values. Each simulation-observation pair gives an error value. This measure sums the values of these errors and divides by the number of forecasts to give an average error. The $M A E$ near 0 , the simulations are good estimate and $M A E=0$ for a perfect estimate (Wilkins, 1995).

\section{Results and discussion}

The observational data used in this study for spatial patterns is the high-resolution 0.25 degree (25 km) gridded data over global land and ocean areas (Huffman et al., 2007) available through the TRMM data set. Other data used measurements made at 25 stations by the Thai Meteorological Department (TMD), selected with $100 \%$ of the data available for November 2011. Litta et al. (2007) used the innermost domain to compare with the observation data, since the results from the innermost domain were a better estimate than other domains. Therefore, this study used the innermost domain to compare with the grid data set and station data set. Fig. 5 shows the spatial distribution of grid observations and different microphysics parameterisation schemes for November 2011. The TRMM data set shows the rainfall distribution with large amounts of rainfall ( $>80 \mathrm{~mm}$ to $160 \mathrm{~mm}$ ) over the south-eastern part of Thailand and over the Malaysian Peninsula ( $>140 \mathrm{~mm}$ to $>200 \mathrm{~mm}$ ), as shown in Fig. 5a. The Kessler scheme (Fig. 5b) shows a large amount of rainfall (>120 $\mathrm{mm}$ to $>200 \mathrm{~mm}$ ) over the south-eastern part of Thailand but can't capture the trend of the large amount of rainfall over the Malaysian Peninsula. The WSM3 scheme (Fig. 5d) shows the trend of a large amount rainfall $(>100$ $\mathrm{mm}$ to $>200 \mathrm{~mm}$ ) over the Malaysian Peninsula. 
Over the south-eastern part of Thailand, the WSM3 underestimates the rainfall ( $>0 \mathrm{~mm}$ to $80 \mathrm{~mm}$ ) compared to the TRMM observation data set. Lin (Fig. 5c), WSM5 (Fig. 5e), WSM6 (Fig. 5f) and the Ensemble mean (Fig. 5g) show the trend of a large amount rainfall $(>100 \mathrm{~mm}$ to $>200 \mathrm{~mm}$ ) over the lower south-eastern part of Thailand. But, it shows less rainfall ( $>0 \mathrm{~mm}$ to $100 \mathrm{~mm}$ ) than in the TRMM observation data set over the central south-eastern part of Thailand. However, all microphysics schemes were showed the accumulated rainfall better agreement with TRMM observation data set.

The comparison of the observed accumulated rainfall for November 2011 with the high resolution model results is shown in Fig. 6. The WSM3 scheme (blue line), WSM5 scheme (black line), WSM6 scheme (green line) and Ensemble mean (purple line) show a trend toward accumulated heavy rainfall over Khor Hong Ago Meteorological Station, Songkhla, Hat Yai Airport, Pattani Airport and Yala Meteorological station. But they underestimated the rainfall over Nakhon Si Thammarat, Nakhon Si Thammarat Meteorological Station, Phatthalung Meteorological Station and Phuket Airport. On the other hand, the Kessler scheme (red line) showed a trend toward accumulated heavy rainfall over Nakhon Si Thammarat, Nakhon Si Thammarat Meterological, Phatthalung Meteorological station, Khor Hong Ago Meteorological Station and Pattani Airport. But it overestimated Ranong, Surat Thani, Samui Island and overestimated even more the heavy rainfall event over Songkhla. The Kessler scheme underestimated the rainfall over the Yala Meteorological station. The orange line (Lin scheme) showed a trend toward accumulated heavy rainfall over Nakhon Si Thammarat, Phatthalung Meteorological Station, Khor Hong Ago Meteorological Station, Songkhla, Hat Yai Airport, Pattani Airport and Yala Meteorological Station, but underestimated over Nakhon Si Thammarat Meteorological Station.

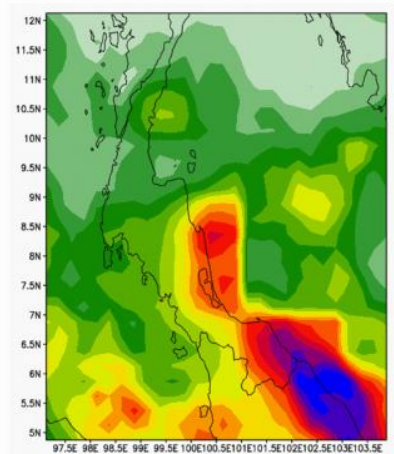

(a)

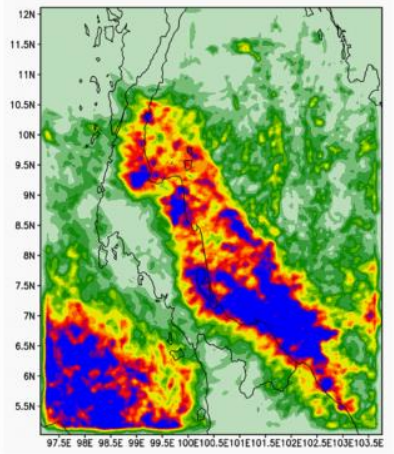

(b)

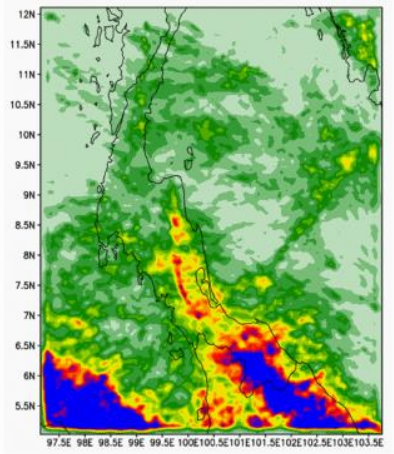

(c)

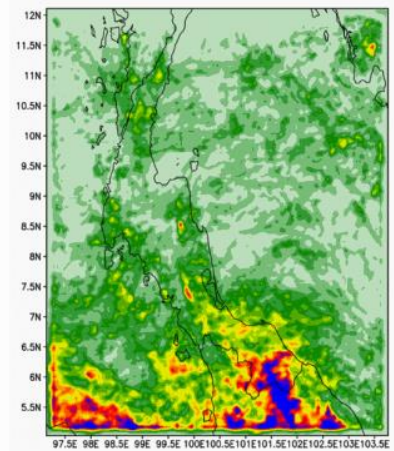

(d)

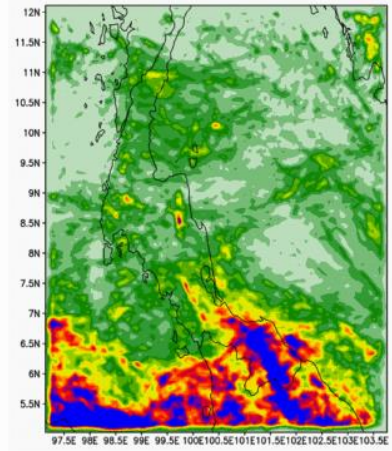

(e)

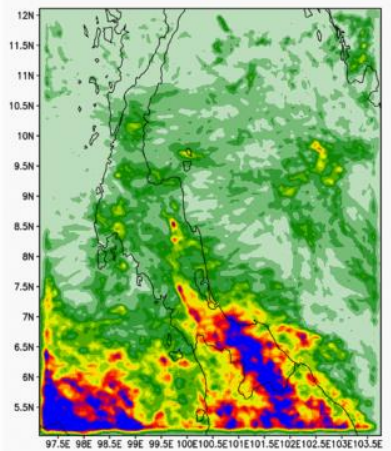

(f)

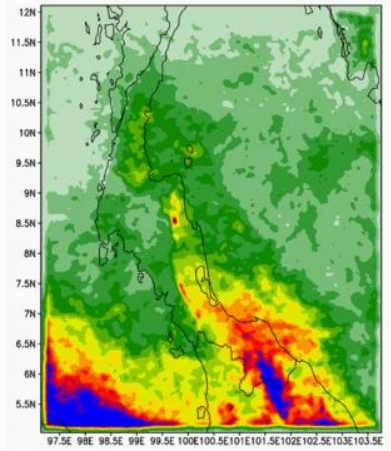

(g)

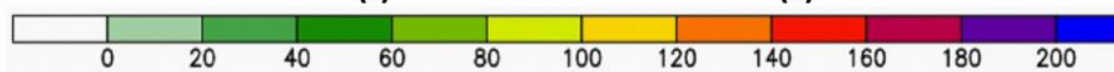

Fig. 5: Spatial distribution of accumulated rainfall $(\mathrm{mm})$ in November 2011 over the southern part of Thailand for the different simulations performed: a) TRMM, b) Kessler, c) Lin, d) WSM3, e) WSM5, f) WSM6 and g) Ensemble mean

However, this study was focused on the heavy rainfall in November 2011 over the southern part of Thailand. The WSM3 scheme (blue line), WSM5 scheme (black line), WSM6 scheme (green line) and Ensemble mean (purple line) captured heavy rainfall events in 5 stations out of 7 station. The Kessler scheme captured heavy rainfall events in 5 stations out of 7 station. But the rainfall was not captured on the same number of stations with WSM3 scheme (blue line), WSM5 scheme (black line), WSM6 scheme (green line) and Ensemble mean (purple line). The Lin scheme captured the heavy rainfall event at more stations than any other scheme, capturing it at 6 out of 7 stations.

The temporal correlation coefficients of the model simulation and observation. The relationship over longer time scales, which are used correlation coefficients for analysis result between observation and model simulated time series, the long timescales are examined following Chotamonsak et al. (2012). 
The running average of the observation and model simulated time series at each station was calculated and the correlation coefficients were calculated at corresponding stations. Fig. 7 shows the correlation coefficients at each station located across southern Thailand. The Kessler scheme (Fig. 7a) and Lin scheme (Fig. $7 \mathrm{~b}$ ) generally showed high correlation coefficients ( $>0.60$ ), but showed low correlation coefficients over Prachuap Khiri Khan (upper southern Thailand) of 0.53 and 0.57 respectively. On the other hand, the correlation coefficients from the WSM3 (Fig. 7c), WSM5 (Fig. 7d), WSM6 (Fig. 7e) and Ensemble mean (Fig. 7f) showed high correlation coefficients $(>0.60)$ at all stations across the southern part of Thailand.
The temporal Mean Absolute Error (MAE) of the model simulation and observation. The concept of the temporal MAE was similar to the temporal correlation coefficients. The running average of the observation and model simulated time series at each station was calculated and the error was calculated at corresponding stations. Fig. 8 shows the MAE at each station location across the Southern part of Thailand. The Kessler (Fig. 8a) scheme showed a good MAE $(<4)$ over the Southern part of Thailand. But a greater MAE (> 4) was shown over Songkhla (4.98). The correlation coefficients from Lin (Fig. 8b), WSM3 (Fig. 8c), WSM5 (Fig. 8d), WSM6 (Fig. 8e) and Ensemble mean (Fig. 8f) showed a good MAE $(<4)$ for all stations across southern Thailand.

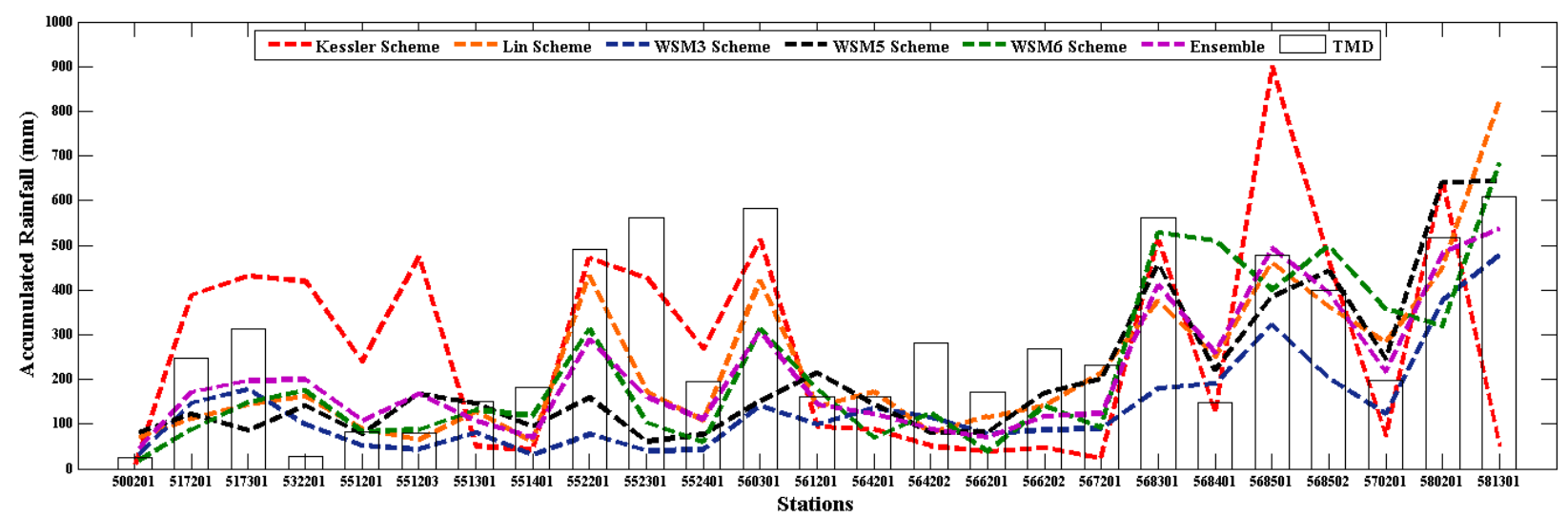

Fig. 6: The comparison of the observed accumulated rainfall in November 2011 with high resolution model results: Kessler scheme (red line), Lin (orange line), WSM3 scheme (blue line), WSM5 scheme (black line), WSM6 scheme (green line) and Ensemble mean (purple line).

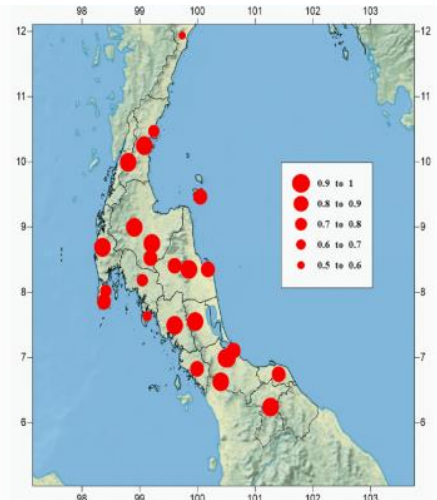

(a)

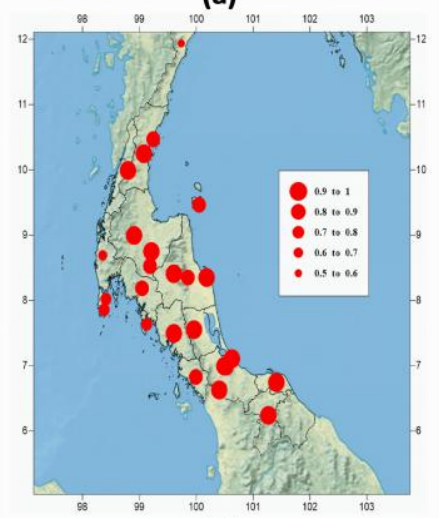

(b)

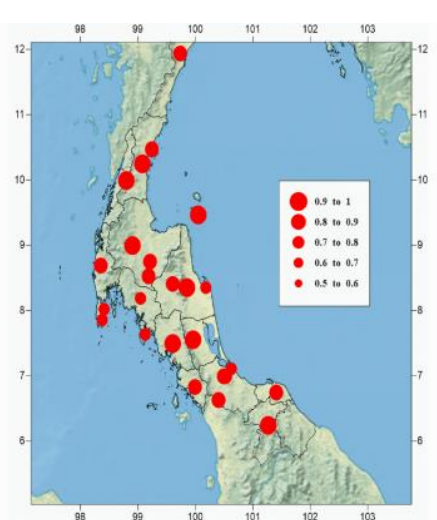

(c)

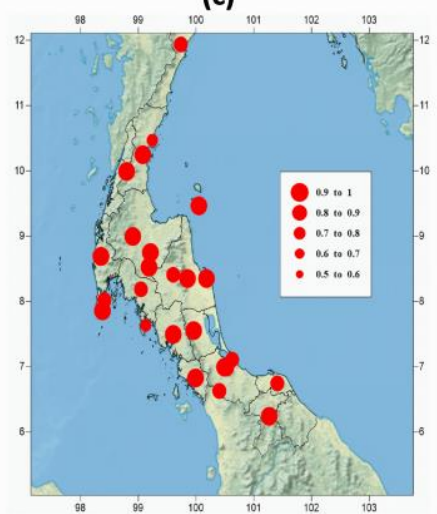

(d)

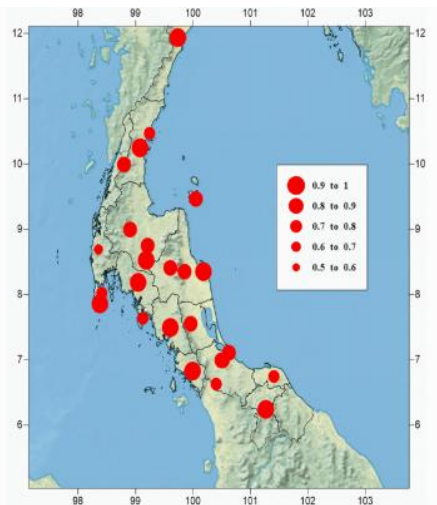

(e)

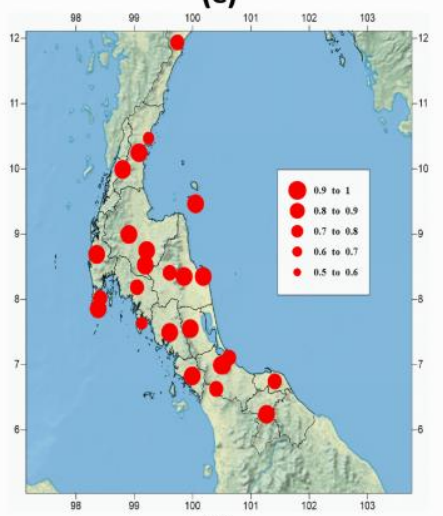

(f)

Fig. 7: The temporal correlation coefficients of the model simulation and observation: a) Kessler, b) Lin, c) WSM3, d) WSM5, e) WSM6 and f) Ensemble mean 
To quantify the ability of four different microphysics parameterizations to produce rainfall over Thailand, average accumulated rainfall, Correlation Coefficient and Mean Absolute Error (MAE) values are presented in Table 3. All the schemes of microphysics with TRMM underestimated the rainfall from station data. The output from the models and TRMM observation data set were also in grid format, with yields lower in intensity than in the point data format. The Kessler scheme showed greater average accumulated rainfall than other schemes in each observation. The Ensemble mean has the highest mean correlation coefficient value at 0.92, with the Lin scheme and WSM5 scheme the next closest at 0.88 . The Kessler scheme, WSM3 scheme and WSM6 scheme have a lower correlation coefficient value of 0.86 when compared with the TMD rainfall station.

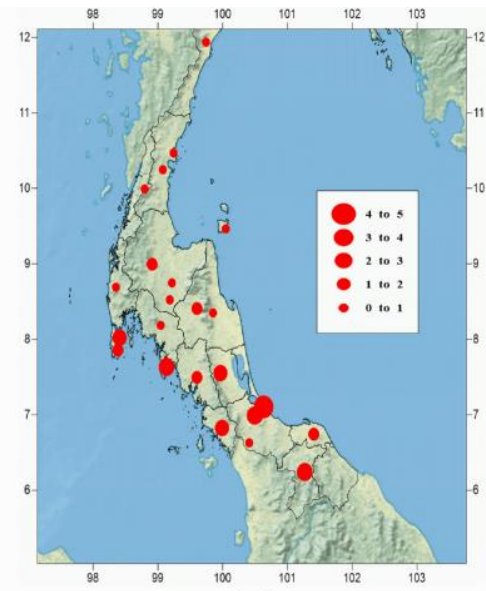

(a)

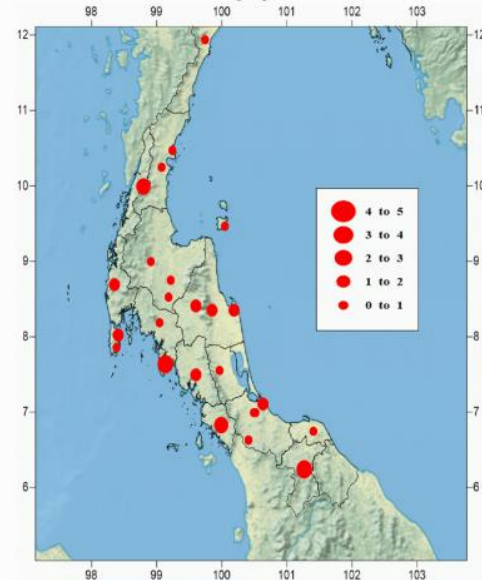

(b)

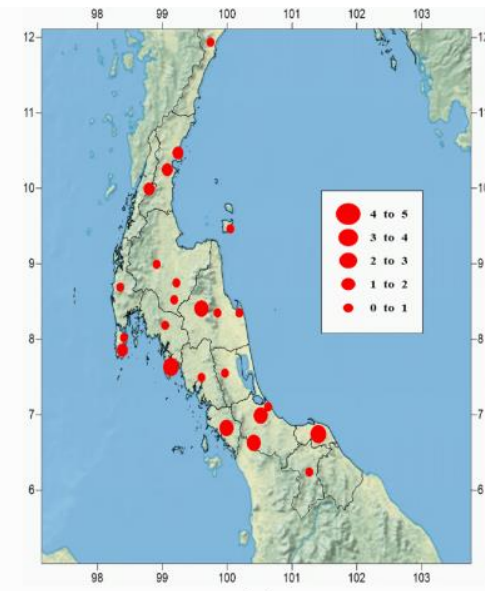

(c)

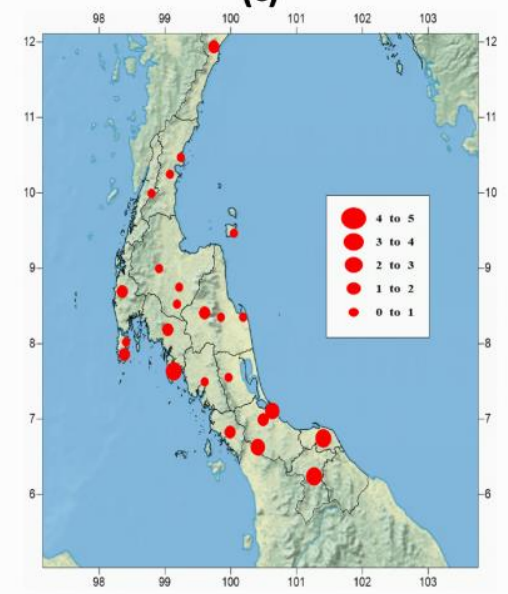

(d)

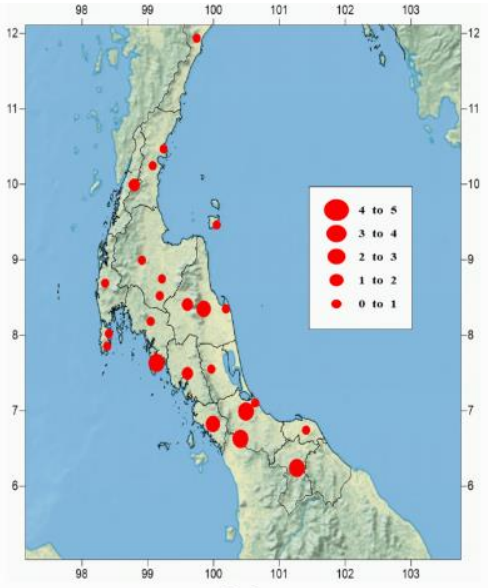

(e)

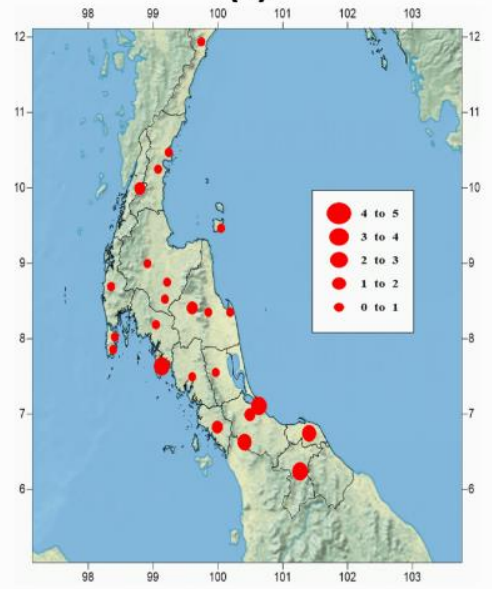

(f)

Fig. 8: The temporal mean absolute error of the model simulation and observation: a) Kessler, b) Lin, c) WSM3, d) WSM5, e) WSM6 and f) Ensemble mean

Table 3: Average accumulated rainfall, correlation coefficient and mean absolute error (MAE) values in November 2011

\begin{tabular}{cccccc} 
& & \multicolumn{2}{c}{ TMD (Average $=285.20 \mathrm{~mm})$} & TRMM (Average $=230.40 \mathrm{~mm}$ ) \\
Microphysics & Average $(\mathrm{mm})$ & MAE & CORR & MAE & CORR \\
Kessler & 273.04 & 1.97 & 0.86 & 1.03 & 0.44 \\
Lin & 232.70 & 1.16 & 0.88 & 0.39 & 0.61 \\
WSM3 & 136.99 & 1.18 & 0.86 & 0.46 & 0.54 \\
WSM5 & 211.40 & 1.47 & 0.88 & 0.56 & 0.61 \\
WSM6 & 222.76 & 1.36 & 0.86 & 0.48 & 0.58 \\
Ensemble & 215.38 & 1.03 & 0.92 & 0.16 & 0.67 \\
\hline
\end{tabular}

The correlation coefficient was compared with the TRMM data. The Ensemble mean showed the mean correlation coefficient value at 0.67 , with the Lin scheme and WSM5 scheme the next closest at 0.61. The Kessler scheme has the lowest correlation coefficient value of 0.44 . For MAE, the Ensemble mean shows the lowest MAE values at 1.03 , with Lin scheme the next lowest at 1.16. The Kessler scheme has the highest MAE value of 1.97 in comparison with the TMD. In comparison with TRMM, the Ensemble mean shows the lowest mean value at 0.16 , with the Lin the next closest at 0.39 . The Kessler scheme has the highest mean value at 1.03. The Ensemble mean simulated lower values than the 
other microphysics parameterizations. However the Lin scheme showed the highest correlation coefficient and lowest MAE than the other microphysics parameterizations, and this scheme has simulated second highest total amount of average rainfall in both observations. Thus, the Lin scheme was able to simulate rainfall more accurately compared with the other microphysics schemes used in this study.

\section{Conclusion}

This study investigated WRF model simulations with several different microphysics schemes for the simulation of heavy rainfall events over the southern part of Thailand. The results imply that the application of the NWP for simulating heavy rainfall over Thailand should account for microphysics schemes to get a better simulation of heavy rainfall in high resolution $(4 \mathrm{~km})$. In conclusion, five different microphysics schemes, including the Ensemble mean, showed results that can be compared with the trend of rainfall spatial distribution in the TRMM observation data set. The results of different microphysics schemes agreed with the TRMM observation data set. The Lin scheme provided good performance values of highest rainfall over the Malaysian Peninsula and south-eastern part of Thailand. In the same way, the Lin scheme showed good estimates of the heavy rainfall event which were close to the TMD station's results. It captured heavy rainfall in 6 out of 7 stations. The statistical comparison method, which used the temporal correlation coefficient and MAE, showed that the Ensemble mean presented the highest correlation coefficient and lowest error compared with the other schemes in both observations, with the Lin and WSM5 schemes the next highest correlation coefficients. But the Lin scheme showed a lower MAE than the WSM5 scheme. In general, the performance of the microphysics schemes of the WRF model gave a good rainfall and good heavy rainfall area prediction, compared with the TRMM observation data set and TMD station over the southern part of Thailand. However, the Lin scheme performed better in simulating spatial distribution and statistics, compared with the other microphysics schemes. The Ensemble mean technique of five schemes was an improved performance of heavy rainfall and shown the good statistics value in this study.

\section{Acknowledgement}

The authors acknowledge NCEP for the FNL data sets, NASA \& JAXA for the TRMM observation data sets, TMD for the station data sets, and NCAR for the WRF model. The authors are also very grateful to the Department of Mathematics, Faculty of Science, King Mongkut's University of Technology Thonburi (KMUTT) for the support. The authors would also like to thank The Joint Graduate School of Energy and Environment for supporting high facility computer. This research was fully supported by the
International Research Network (IRN) (IRN5701PDW0002).

\section{References}

Chotamonsak C, Salate Jr PE, Kreasuwan J, and Chantara S (2012). Evaluation of Precipitation Simulations over Thailand using a WRF regional climate model. Chiang Mai Journal of Science, 39(4): 623-638.

Dudhia J (1989). Numerical study of convection observed during the winter monsoon experiment using a mesoscale twodimensional model. Journal of the Atmospheric Sciences, 46(20): 3077-3107.

Efstathiou GA, Zoumakis NM, Melas D, and Kassomenos P (2012). Impact of precipitation ice on the simulation of a heavy rainfall event with advanced research WRF using two bulk microphysical schemes. Asia-Pacific Journal Atmospheric Science, 48(4): 357-368

El Afandi G, Morsy, M, and El Hussieny F (2013). Heavy rainfall simulation over Sinai Peninsula using the weather research and forecasting model. International Journal of Atmospheric Sciences, 2013: Article ID 241050, 11 pages. https://doi.org/10.1155/2013/241050

Hong SY and Lim JOJ (2006). The WRF single-moment 6-class microphysics scheme (WSM6). Journal of the Korean Meteorological Society, 42(2): 129-151.

Hong SY, Dudhia J, and Chen SH (2004). A revised approach to ice microphysical processes for the bulk parameterization of clouds and precipitation. Monthly Weather Review, 132(1): 103-120.

Hong SY, Noh Y, and Dudhia J (2005). A new vertical diffusion package with an explicit treatment of entrainment processes. Monthly Weather Review, 134(9): 2318-2341.

Huffman GJ, Adler RF, Bolvin DT, Gu G, Enelkin EJ, Bowman KP, Stocker EF, and Wolff DB (2007). The TRMM multi-satellite precipitation analysis: quasi-global, multi-year, combinedsensor precipitation estimates at fine scale. Journal of Hydrometeorol, 8(1): 38-55.

Janjic ZI (1994). The step-mountain eta coordinate model: Further developments of the convection, viscous sublayer, and turbulence closure schemes. Monthly Weather Review, 122(5): 927-945.

Kaewmesri P, Humphries U, Wangwongchai A, Wongwies P, Arche Varapuprok B, and Sooktawee S (2017). The simulation of heavy rainfall events over Thailand using microphysics schemes in weather research and forecasting (WRF) model. World Applied Sciences Journal, 35(2): 310-315.

Kessler E (1995). On the continuity and distribution of water substance in atmospheric circulations. Atmospheric Research, 38(1-4): 109-145.

Kirtsaeng S, Chantar S, and Kreasuwan J (2010). Mesoscale simulation of a very heavy rainfall event over mumbai, using the weather research and forecasting (WRF) model. Chiang Mai Journal Science, 37(3): 429-442.

Kirtsaeng S, Kreasueun J, Chantara S, Kirtsaeng S, Sukthawee P, and Masthawee $F$ (2012). Weather research and forecasting (WRF) model performance for a simulation of the 5 November 2009 heavy rainfall over southeast of Thailand. Chiang Mai Journal Sciences, 39(3): 511-523.

Lim JOJ, and Hong SY (2005). Effects of bulk ice microphysics on the simulated monsoonal precipitation over East Asia. Journal of Geophysical Research: Atmospheres, 110(D24). Available online at: http://onlinelibrary.wiley.com/doi/10.1029/2005J D006166/full

Lin YL, Ferley RD, and Orvillie HD (1983). Bulk parameterization of the snow field in a cloud model. Journal of Climate and Applied Meteorology, 22(6): 1065-1092. 
Litta AJ, Chakrapani B, and Mohankumar K (2007). Mesoscale simulation of an extreme rainfall event over Mumbai, India using a high-resolution MM5 model. Meteorological Applications, 14(3): 291-295.

Mlawer Eli J, Taubman SJ, Brown DP, Iacono MJ, and Clough SA (1997). Radiative transfer for inhomogeneous atmospheres: RRTM, a validated correlated-k model for the longwave. Journal of Geophysical Research: Atmospheres, 102(D14): 16663-16682.

Pennelly C, Reuter G, and Flesch T (2014). Verification of the WRF model for simulating heavy precipitation in Alberta. Atmospheric Research, 135: 172-192.

Skamarock WC, Klemp JB, Dudhia J, Gill DO, Barker DM, Duda MG, Huang XY, Wang W, and Powers JG (2008). A description of the advance research WRF Version 3. National Center for Atmospheric Research, Boulder, Colorado, USA.

Tewari M, Chen F, Wang W, Dudhia J, LeMone MA, Mitchell K, Ek M, Gayno G, Wegiel J, and Cuenca RH (2004). Implementation and verification of the unified NOAH land surface model in the WRF model. In the $20^{\text {th }}$ Conference on Weather Analysis and Forecasting $/ 16^{\text {th }}$ Conference on Numerical Weather Prediction, USA: 11-15.

Wangwongchai A, Sixiong Z, and Qingcun Z (2005). A case study on a strong tropical disturbance and record heavy rainfall in Hat Yai Thailand during the winter monsoon. Advance in Atmospheric Sciences, 22(3): 426-450.

Wilkins D (1995). Statistical Methods in the atmospheric sciences. Academic Press, San Diego, USA. 